University of Pennsylvania Carey Law School

Penn Law: Legal Scholarship Repository

Faculty Scholarship at Penn Law

$1-9-2007$

\title{
How Psychology is Changing the Punishment Theory Debate
}

Paul H. Robinson

University of Pennsylvania Carey Law School

Follow this and additional works at: https://scholarship.law.upenn.edu/faculty_scholarship

Part of the Criminal Law Commons, Law and Psychology Commons, Public Law and Legal Theory Commons, and the Social Psychology Commons

\section{Repository Citation}

Robinson, Paul H., "How Psychology is Changing the Punishment Theory Debate" (2007). Faculty Scholarship at Penn Law. 132.

https://scholarship.law.upenn.edu/faculty_scholarship/132

This Article is brought to you for free and open access by Penn Law: Legal Scholarship Repository. It has been accepted for inclusion in Faculty Scholarship at Penn Law by an authorized administrator of Penn Law: Legal Scholarship Repository. For more information, please contact PennlawIR@law.upenn.edu. 


\title{
6 \\ How Psychology is Changing the Punishment Theory Debate
}

\author{
Paul H Robinson*
}

These are exciting times in punishment theory. For nearly a half century there have been what seem like irreconcilable disagreements about how punishment should be distributed. The deontologists argue for a distribution that tracks an offender's blameworthiness. The utilitarians urge a distribution of punishment that maximizes deterrents or rehabilitation or incapacitation, whichever will best reduce future crime. For the deontologists, doing justice is a value in itself and needs no further justification. For the utilitarians, some future benefit is required to justify the imposition of punishment. The desert-based distribution of the deontologists looks almost exclusively to the past, focusing on the conduct and state of mind of the offender at the time of the offence. The utilitarian calculations look primarily to the future: how to avoid future crime most effectively.

This irreconcilable dispute is not simply academic. Penal code writers, sentencing guideline drafters, judges interpreting the provisions of either, and judges exercising sentencing discretion all were caught in the middle of this apparently irreconcilable disagreement. According to which of the alternative guiding principles should the code or guideline provision be drafted or interpreted or should sentencing discretion be exercised?

The Model Penal Code, promulgated in 1962 by the American Law Institute, reflected the ambivalence of the situation: when it set out the purposes of the criminal code and the purposes that should guide its interpretation and its grant of discretion in Section 1.02, it listed all of these alternative principles for the distribution of liability and punishment without distinguishing among them. Because it did not define the interrelation among these alternative distributive principles, it presented a significant practical problem. Different distributive principles produce different punishment results and the absence of a defined interrelation among the alternative principles fails to give a decision maker needed guidance as to which principle to follow when they conflict. In sentencing the

\footnotetext{
*The author thanks Thomas O'Brien and Cat-Uyen Vo for their useful research assistance.
} 
elderly Nazi concentration camp torturer, for example, a dangerousness distributive principle would suggest no punishment while a desert or general deterrence distributive principle would suggest significant punishment. On the other hand, it is not unusual to have an offender commit a minor offence but under circumstances that predict future more serious offences, which similarly would suggest quite different sentences depending upon whether the distributive principle is incapacitation of the dangerousness or deterrence or desert.

What is exciting about our present times is that the stalemate of the last several decades has been, if not broken, significantly altered to avoid the practical problems. A recent report of the American Law Institute illustrates the point. It proposes changing the Code's 'purposes' section, Section 1.02. This is the first proposed change to the Model Penal Code since its promulgation in 1962. I will talk more about the proposed change later. ${ }^{1}$

What has changed in the punishment theory debate and why? The answers to these questions put psychology in a prominent role. Let me briefly describe the contribution that it has made, which has come from the cumulative effect of many very different aspects of psychology.

The changes are of two sorts. First is a general disappointment in the effectiveness of the utilitarian distributive principles of deterrence, rehabilitation, and incapacitation of the dangerous. Let me give a quick walk through the basis for this disappointment, taking up each of these alternative utilitarian mechanisms in turn.

\section{Deterrence}

The dominant distributive principle of the past several decades has been deterrence. Any distributive principle for punishment will provide some kind of deterrent effect by virtue of its threat of sanction upon violation. But setting deterrence as the distributive principle for liability and punishment means having liability and punishment rules formulated to maximize deterrent effect. And it is this project-formulating liability and punishment rules to maximize deterrence-about which there is increasing reason for scepticism. ${ }^{2}$

Effective deterrence requires at least three things. First, for a particular code rule formulation or sentencing policy to have deterrent effect, the target of that deterrent effect must know of the rule formulation or policy. Yet the existing studies suggest that this is rarely the case. People often think they know the legal rule but are commonly wrong. Most frequently, people think the rule is as they think it should be-their own intuitions about what a just rule would be-in other

1 See Preliminary Draft, $\mathrm{n} 24$ below.

2 See generally P Robinson and J Darley, 'Does Criminal Law Deter? A Behavioral Science Investigation' [hereinafter 'Deter'], (2004) 24 OJLS 173; P Robinson and J Darley, 'The Role of Deterrence in the Formulation of Criminal Law Rules: At Its Worst When Doing Its Best' [hereinafter 'Role'] (2003) 91 Georgetown Law Journal 949. 
words, they assume desert-based rules. But a deterrence-based rule can provide greater deterrence than a desert-based rule. It can only do so by deviating from desert, in other words, by deviating from the rule that people assume exists. Thus, the very instances in which the deterrence-based rule could provide more deterrence are just those situations in which people will not know the deterrence-based rule. $^{3}$

Secondly, to have an effective deterrent effect, a target must be able to bring knowledge of the rule to bear on his own conduct. Yet the evidence is that drugs, alcohol, anger, fear, group arousal, group identity shift, impulsiveness, and other distortion effects are common in situations in which crimes are committed and are in fact disproportionately greater in the very people that are meant to be the target of the deterrent threat. ${ }^{4}$ Thus, even if a person knew of the rule that was designed to deter his conduct, the chances are high that the rule would have no effect on him because one of these common distorting effects would be present to prevent the person from bringing the knowledge of the rule to bear in avoiding the violation.

Finally, even if an actor knows of the rule and has the capacity to bring the rule to bear in governing his conduct, there will be no deterrent effect unless the person perceives that the cost of engaging in the prohibited conduct is greater than the perceived benefits of doing so. Bentham famously suggests that the decision here will depend upon the actor's perceptions of three specific aspects of the threat: the probability of punishment, the intensity (or amount) of punishment, and the delay between violation and punishment. ${ }^{5}$

As to the perceived probability of punishment, there is good reason to think that the present criminal justice system does not present a terribly effective deterrent threat. Consider, for example, animal studies that demonstrate the importance of probability of punishment. In one study, for example, if pigeons are trained to get food by pressing a bar and then are shocked when they press the bar, the shock can deter further pressing. If the frequency with which they are shocked is decreased from 100 per cent to 50 per cent, the result is a 30 per cent decrease in the suppression of the conduct. If the frequency is reduced to being shocked 10 per cent of the time, suppression disappears. This illustrates that the probability of punishment can have a real effect. One, of course, must have some caution in applying lessons from studies of lower animals to the conduct of humans, but it does at least give us some pause when we realize that the probability of punishment in the criminal justice system is for most offences quite low, 100 to 1 or 50 to 1 . (It is only for offences like homicide or aggravated assault that the punishment rate increases to 50 per cent for homicide and something less for aggravated assault.) ${ }^{6}$

3 Robinson and Darley, 'Role', n 2 above, 983-92.

4 Robinson and Darley, 'Deter', n 2 above, 178-82.

5 J Bentham, The Theory of Legislation (1931 edn) 322-6, 336. See also Robinson and Darley, 'Deter', n 2 above, 175-97.

6 Robinson and Darley, ibid, 193-5. 
Oddly, what helps us in this respect is that other studies confirm that humans tend to exaggerate the probability of rare events. Thus, the targets of deterrence may overestimate the likelihood of punishment. ${ }^{7}$ The difficulty here is that those persons who are most prone toward committing criminal offences are the persons who have special incentives to sort out exactly what the real probabilities are. Anderson concludes after his studies of offenders in prison that 76 per cent of active offenders committing serious offences simply do not think seriously about the possibility of punishment in their calculations and are therefore willing to commit the offence. ${ }^{8}$

The second factor-the perceived amount of punishment threatened-presents a somewhat different situation. There is no question that it is within the ability of the criminal justice system to impose some punishment bite. But a successful deterrence programme requires something more; it requires that the amount of punishment be modulated to achieve the deterrent purpose. For example, a deterrence-based system requires, all other things being equal, a threat of greater punishment for more serious offences than for less serious offences. This assures, for example, that some additional deterrent threat is available to deter an offender who has committed an offence from further committing some more serious offence. ${ }^{9}$

But the available studies suggest that the dynamics at work here are very complex and unpredictable given our current amount of information. First, we know that people's perception of the amount of punishment threatened will be discounted by the fact that it does not occur immediately but will occur at some time in the sometimes distant future. A different kind of complexity is seen in animal studies again. If pigeons are trained to get food by pushing a lever, then are shocked to deter them from pressing it, a certain level of shock will deter, in one study 80 volts. But consider the effect when the pigeon is initially shocked only with 60 volts - which will not suppress the pushing - and then shocked with 70, then 80 volts, and so on, increasing the voltage incrementally, an efficient approach in a deterrence system for finding the point of suppression (so as not to punish more than is needed). With the incremental increases, the 80 volt shock will no longer suppress the conduct. It is as if the earlier shockings have taught the pigeon that it can in fact withstand the shock. In fact, in this study, the voltage was increased incrementally to 300 volts before it suppressed the conduct. This could make one somewhat uncomfortable about our standard practice of giving low punishment to a first time offender and then increasing it upon each repetition of the conduct. The incremental increase approach may make good sense from a deterrence point of view-it supposedly avoids the waste of punishment in excess

7 See ibid, 184.

8 D Anderson, 'The Deterrence Hypothesis and Picking Pockets at the Pickpocket's Hanging' (2002) 4 American Law and Economic Review 295.

9 Robinson and Darley, 'Deter', n 2 above, 185-6. 
of that necessary to deter conduct-but its effect may simply be to educate offenders that they can in fact withstand the punishment threatened. ${ }^{10}$

Another sort of complexity is found in the 'subjective well being' studies. Both lottery winners and paraplegics from car accidents have a natural tendency to revert back to their prior affective state with the passage of time; they are no more or less well off emotionally than before the chance event. This reflects what we know to be the normal human capacity to adapt to one's situation. This same adaptive mechanism works in relation to imprisonment as well. The punitive bite of the prison experience is greatest at the start, which is why most prison suicides occur in the first few days of imprisonment. The punitive bite decreases over time as the person adapts to their situation, and adjusts their expectations accordingly. The effect of this is that punishment becomes increasingly less cost efficient. The cost of imprisonment is the same for each unit of time-often US $\$ 30,000$ per year-but the punitive bite that we get from each year's punishment decreases over time, such that the cost per punishment unit increases as the prison term gets longer. ${ }^{11}$

But in fact this adaptive mechanism has even more seriously complicating effects when combined with what is called the 'duration neglect' effect. Daniel Kahneman reports a study in which he gives a minor medical-like operation with a certain amount of pain for a certain duration and then gives the subject a second operation that has the same amount of pain for the exact same duration as the first but continues for an additional period without a break during which the amount of the pain is gradually reduced. He then tells the subject that one of the two procedures needs to be repeated and asks subjects which they would prefer to repeat. They prefer to repeat the second rather than the first, even though it has all of the pain of the first and more! What the experiment demonstrates is that it is not the duration of the pain that is of significance but rather two other factors: the maximum intensity and the end point intensity. Because the second operation reduced the pain at the end, it reduced the end point intensity and thereby became perceived as less painful. ${ }^{12}$

The effect of duration neglect for imprisonment practices is quite troubling. With the natural adaptation effect that reduces the punitive bite of prison as the period becomes longer, the end point intensity decreases over time with the possibility that a longer prison term may be perceived as having less punitive bite than a shorter prison term! These results have not been confirmed with human subjects but the point here is simply to illustrate the level of complexity of the dynamics at work in a deterrence system and to suggest that that complexity is at the moment well beyond our ability reliably to predict deterrent effects and to modulate punitive bite as a deterrence-based system requires.

10 Robinson and Darley, 'Deter', n 2 above, 186-7.

12 D Redelmeier and D Kahneman, "Patients" Memories of Painful Medical Treatments: Real Time and Retrospective Evaluations of Two Minimally Invasive Procedures' (1996) 116 Pain 3. 
The last factor that affects the perceived extent of a deterrent threat is the delay between the punishment and the violation. Consider the study of hungry dogs who were given two bowls of food, one tasty, one not. Once the dogs had come to understand their preference, an experimenter strikes the dog on the nose with a newspaper-which I am told is quite painful to dogs-as soon as the dog eats from the preferred bowl, or 5 seconds after he eats from the preferred bowl, or 15 seconds after he eats. The dogs are then let back into the room with the experimenter not present and are timed to see how long it takes them to return to eat from the preferred bowl. The dogs for whom the punishment was delayed by 15 seconds return to the preferred bowl in 3 minutes. The dogs for whom the punishment was delayed only 5 seconds take dramatically longer to return to the preferred bowl, 8 days. The dogs who were punished immediately did not return to the preferred bowl for 2 weeks. Again, the point here is to demonstrate that delay in punishment can have a very dramatic effect in the effectiveness of punishment. One cannot directly translate these results to the effect of delay in punishment on humans but it is again somewhat unsettling when one appreciates that in the criminal justice system the punishment is typically delayed 7 months on average for guilty pleas and 13 months on average for trial. ${ }^{13}$

Compare these troubling results for the criminal justice system in projecting a perception of serious costs to a violation as compared to the perceived benefits of the violation. The probability of gaining the benefit is likely to be seen as high, because the perceived chances of being caught are low. The amount of the benefit typically is quite clear, and can be overwhelming if the person is an addict committing the offense to buy drugs, which is common. Finally, the delay in benefits will be minimal, since it will come soon after the violation, in contrast to perceived long delay before the threatened punishment. On balance, it seems difficult to imagine that the perceived costs will exceed the perceived benefits.

The larger point here in relation to deterrence as a distributive principle is to say that tripping any one of these three hurdles - a failure to know the deterrencebase rule, an inability to bring that rule to bear on one's conduct, or a failure to perceive the cost of a violation as exceeding its benefits-is fatal to any deterrent effect. Further, even if all of these three hurdles can be cleared, it will not be uncommon to have some kind of cumulative disabling effect. For example, a person may know the rule but be a bit fuzzy on its contours, may be able to control his conduct to some extent yet have some impairment in full clarity and control, and may perceive some potential cost to a violation but may see the perceived cost and the perceived benefits as quite close in amount. But even if the system's intended deterrent effect is not lost by stumbling over one of the three hurdles, which may be the rule rather than the exception, the remaining deterrent effect in the lucky case described immediately above may be one of trivial

13 RL Solomon, LH Turner, and MS Lessac, 'Some Effects of Delay of Punishment on Resistance to Temptation in Dogs' (1968) 8 Journal of Personality and Social Psychology 233. 
deterrent effect. Indeed, if one looks at studies of rule or policy changes designed to increase deterrent effect, the results suggest that success is rare and, where it does exists, is modest or trivial, and unpredictable. ${ }^{14}$

The conclusion that one can draw from all of this is that constructing liability and punishment rules and policies based on a deterrence distributive principle makes little sense unless there is reason to believe that the prerequisites to deterrence exist and that we have the information and the understanding needed to know how to produce the desired deterrent effect. The difficulty is that those situations seem to be very much the exception rather than the rule.

\section{Rehabilitation}

There is every reason to try to rehabilitate offenders. Even if its success is quite modest, as seems to be the case, its use commonly can justify the costs. But the issue at stake here is not whether to try to rehabilitate but rather whether to use rehabilitation as the guiding principle in deciding whom and how much to punish.

It seems difficult to conceive of a criminal justice system that took seriously rehabilitation as its primary distributive principle, for such a system would distribute punishment based solely upon whether somebody could be rehabilitated. And the possibility of such might well be the unusual case, in which case most offenders would not be punished. There would seem to be few people who would take this view, in part because it would so seriously conflict with what people conceive of as what a 'criminal justice' system ought to be doing. That is, such a distribution would regularly fail to do justice and fail to protect the community.

What makes somewhat more sense would be using rehabilitation not as a sole distributive principle for punishment liability but rather as part of a dual principle with incapacitation of the dangerous. Persons would be rehabilitated if possible and, if not, would be preventively detained while they remained dangerous.

\section{Incapacitation}

Unlike deterrence and rehabilitation, whose effectiveness seems to be quite limited, it seems relatively clear that incapacitation does work. Putting potential offenders in prison or otherwise incapacitating them so they cannot commit offenses (at least offenses against the community outside of prison) can avoid crimes. The complications with using incapacitation as a distributive principle in whole or in part lies in the fact that, while it can provide some protection, it provides much less protection than would be possible, and at a much greater cost than 
would be necessary, if such preventive detention were provided openly, rather than if it were provided in the guise of criminal justice. ${ }^{15}$

That is, if a society wishes to have a system of preventive detention that restricts people's liberty not for a past wrong done but based upon a prediction of future dangerousness, then that preventive program can more effectively, more fairly, and more cheaply be provided by an open preventive detention system of a civil nature-analogous to the current system for the civil commitment of persons who are dangerously mentally ill, infected with a contagious disease, or, in some jurisdictions, addicted to drugs-rather than attempting to dress such preventive detention up as criminal justice.

To give just one example, when preventive detention is pursued through a criminal justice system, the prediction of future dangerousness typically is not done simply through a clinical examination by those best trained to predict future criminality using all available information. Instead, to keep the appearance of criminal justice, the prediction of future dangerousness is made instead by a correlate of future dangerousness-prior criminal conduct-that seems more relevant to doing justice. Our ability to predict future criminality under the best of circumstances is quite limited; the effectiveness of past criminal conduct to predict future criminal conduct is even worse. ${ }^{16}$ By relying upon this significantly less reliable predictor, we either provide less protection to society than we could provide under an open preventive detention system or we produce more unfairness by imprisoning more 'false positives'- persons who would not in fact commit an offense if they had not been imprisoned-or we do both, getting worse protection while causing greater unfairness. In other words, that kind of flawed system-relying upon less accurate predictive factors than necessary in order to disguise the system as being one of criminal justice rather than preventive detention - is both unfair to persons to be detained and to the community to be protected. ${ }^{17}$

But these inefficiencies and unfairness are not the most serious problem with an incapacitative distributive principle for criminal justice. The real problem is that an incapacitation distributive principle (either combined with a rehabilitation principle or not) produces distributions of criminal liability and punishment that seriously conflict with principles of justice that the community shares and that they expect to be embodied in their criminal justice system. And the perception of a criminal justice system that regularly does injustice in some cases and fails to do justice in others is something that will have its own effect in undercutting efficient crime control. ${ }^{18}$ This is the second general development in punishment theory to which psychology has contributed: it has led us to understand that the real power

15 See generally P Robinson, 'Punishing Dangerousness: Cloaking Preventative Detention as Criminal Justice' (2001) 114 Harvard Law Review 1429, 1450-4.

17 ibid, 1451-5.

18 ibid, 1439-41, 1443-4. 
of control over people's conduct is not the threat of official sanction but rather the power of social influence and internalized norms. ${ }^{19}$

\section{The Crimogenic Effect of Injustices and Failures of Justice}

The effective operation of the criminal justice system depends upon the cooperation, or at least the acquiescence, of those involved in it-offenders, judges, jurors, witnesses, prosecutors, police, and others. To the extent that people see the system as unjust, as in conflict with their own intuitions about justice, that acquiescence and cooperation is likely to fade and be replaced with subversion.

Consider the effect of an incapacitation distributive principle on the system's reputation for doing justice. The elderly Nazi concentration camp commandant may be perceived as deserving significant punishment but, because he is not dangerous, no preventive detention is required and an incapacitation distributive principle would impose no punishment. On the other hand, a minor offence, meriting little if any punishment, may be committed by a person who is predicted to be dangerous in the future, and consequently would receive substantial punishment under an incapacitation principle. Thus, an incapacitative principle will undercut the criminal justice system's reputation for doing justice.

Note that a desert-based system does necessarily provide some degree of preventive detention as it imposes deserved punishment. Thus, an incapacitationbased system can provide greater preventive detention only in those instances where it deviates from a desert distribution. In other words, the traditional utilitarian mechanisms are preferred over a desert distribution only to the extent that they deviate from desert. But it is just these deviations from desert-injustices or failures of justice-which will prompt subversion of the system as well as other detrimental effects.

\section{The Power of Social Influence and Internalized Norms, and Criminal Law's Ability to Harness that Power}

The other detrimental effects to which I refer here may in practice be the more important. While the real power of social control lies in social influence and internalized norms, law is not irrelevant to these powers. A criminal law that has gained a reputation for reliably stating what is and is not morally condemnable from the point of view of the community, is a criminal law that can have positive influence in guiding conduct in borderline cases where the community may not yet have a clear sense of whether conduct is condemnable or not. Consider, for example,

19 P Robinson and J Darley, 'The Utility of Desert' (1997) 91 Northwestern University Law Review $453,468-71$. 
insider trading. We live in a complex society in which many harms are more abstract and more subtle than taking others' property or striking another over the head. Insider-trading is conduct that on its face may not seem clearly condemnable but if the criminal law announces it to be so and that criminal law has otherwise earned credibility with the community in making reliable judgements regarding what is condemnable, the community may be more inclined to see the conduct as condemnable and therefore to be avoided. ${ }^{20}$

Law may have an even more powerful impact in another way: in its ability to shape community norms generally. Drunk driving, domestic violence, and date rape are all instances in which we have seen changes in community views and in the common internalization of norms. The law cannot shape these kinds of changes in norms by itself; calling something criminal by itself cannot make it condemnable. This is in part the lesson of Prohibition in the United States. However, the law can be an active participant in the public discussions that do effectively shape norms when it adds its voice to that of the larger discussion. ${ }^{21}$

But these effects-gaining compliance in borderline cases and in shaping norms - are possible only if the criminal law has earned moral credibility with the community. To the extent that the criminal law distributes liability and punishment based upon distributive principles that conflict with the community's shared intuitions of justice-deterrence, rehabilitation, and incapacitation would all do-the criminal law's moral credibility is undercut and its ability to harness these powerful effects in influencing conduct is undermined. ${ }^{22}$

\section{The Utility of Desert}

The conclusion that one can come to on these facts is that the utilitarian who wishes to avoid future crime most effectively may well end up preferring a desert distribution of liability and punishment. By tracking a community's shared intuitions of justice, the criminal law can build its moral credibility and then use that influence in select situations, such as drunk driving, domestic violence, and date rape, to help shape community norms. ${ }^{23}$

The most striking thing about this conclusion, of course, is that this argument in support of a desert distributive principle is utilitarian in nature rather than deontological. In other words, while the dispute of the past half century has been resolved, as a practical matter it has come to common ground. The deontologists still believe that doing justice is a value in itself and requires no beneficial future consequences to justify it, while utilitarians still can only justify punishment if it produces future beneficial consequences, such as reducing crime. But both utilitarians and deontologists may come to the same conclusions of preferring a desert distributive principle, albeit for quite different reasons.

20 ibid.

21 ibid, 471-6.

22 ibid, 477-8.

23 ibid, 485-8. 
In light of this background, it should be no surprise to hear that the American Law Institute committee's proposal for revising the Model Penal Code's 'purposes' section is one that would give complete priority to doing justice. Under the proposal, the traditional utilitarian mechanisms of deterrence, rehabilitation, and incapacitation can be given play only if they are not inconsistent with an offender's deserved punishment and if there is some evidence to think that they would be effective in that situation. ${ }^{24}$

24 The text of the proposal provides:

$\$ 1.02(2)$. Purposes; Principles of Construction.

(2) The general purposes of the provisions governing sentencing and corrections, to be discharged by the many official actors within the sentencing and corrections system, are:

(a) in decisions affecting the sentencing and correction of individual offenders:

(i) to render punishment within a range of severity proportionate to the gravity of offenses, the harms done to crime victims, and the blameworthiness of offenders;

(ii) when possible with realistic prospect of success, to serve goals of offender rehabilitation, general deterrence, incapacitation of dangerous offenders, and restoration of crime victims and communities, provided that these goals are pursued within the boundaries of sentence severity permitted in subsection (a) (i) and (ii); and

(iii) to render sentences no more severe than necessary to achieve the applicable purposes from subsections (a)(i) and (ii); ...

Model Penal Code: Sentencing, Preliminary Draft No 3 (28 May 2004) 4-5. 


\title{
Law and Psychology \\ Current Legal Issues 2006
}

\section{VOLUME 9}

\author{
Edited by \\ BELINDA BROOKS-GORDON \\ Lecturer in Psychology \\ Birkbeck College, London \\ and \\ MICHAEL FREEMAN \\ Professor of English Law \\ University College London
}

\section{OXFORD \\ UNIVERSITY PRESS}

